\title{
Chylothorax and chylous ascites due to heart failure
}

\author{
V. Villena, A. de Pablo, P. Martín-Escribano
}

Chylothorax and chylous ascites due to heart failure. V. Villena, A. de Pablo, P. MartínEscribano. CERS Journals Ltd 1995.

ABSTRACT: Chylous ascites and chylothorax have rarely been reported as a consequence of severe right heart failure. To our knowledge, this is the first case report of both disorders occurring as a result of ischaemic cardiomyopathy. The autopsy findings and possible mechanisms of production are discussed.

Eur Respir J., 1995, 8, 1235-1236.
Servicio de Neumología, Hospital Universitario 12 de Octubre, Madrid, Spain.

Correspondence: V. Villena

Servicio de Neumologia

Hospital 12 de Octubre

Carretera de Andalucía Km 5.4

28041 Madrid

Spain

Keywords: chylothorax, chylous ascites, Heart failure

Received: December 7 1994, Accepted after revision March 281995
Chylothorax and chylous ascites are most commonly associated with trauma or neoplasm. Constrictive pericarditis, dilated cardiomyopathy, and ischaemic heart disease have sometimes been associated with chylous ascites [1-4], and rheumatic mitral stenosis has occurred with chylothorax [5, 6]. Nevertheless, to our knowledge, this is the first reported case with heart failure associated both with chylothorax and chylous ascites. It is important to consider heart failure among the causes of both disorders.

\section{Case report}

An 84 year old white woman was admitted following development of progresive dyspnoea, orthopnoea, abdominal distension and ankle oedema in the previous few days. She had had a myocardial infarction in 1990 and a history of arterial hypertension. She had been receiving diuretic treatment for several months.

On physical examination the patient was obese and had anasarca. Her blood pressure was 130/80 $\mathrm{mmHg}$ and her jugular venous pressure was high. On pulmonary auscultation no sounds were found over the left lower lobe. Abdominal examination revealed severe ascites and the lower extremities were severely oedematous.

Blood laboratory studies were normal. Serum total protein was $69 \mathrm{~g} \cdot \mathrm{L}^{-1}$ with an albumin concentration of $39 \mathrm{~g} \cdot \mathrm{L}^{-1}$. Chest radiography showed pleural effusion covering the lower half of the left hemithorax and cardiomegaly. Thoracocentesis and paracentesis disclosed a milky fluid, the biochemical characteristics of which are shown in table 1. Cytological analysis and Löwenstein culture of both fluids were negative. Echocardiogram with Doppler examination revealed decreased ventricular contractility, pulmonary hypertension, and moderate aortic and tricuspid insufficiency. Computed tomography
(CT) of the chest and abdomen showed no abnormal masses or enlarged lymph nodes. Gynaecological ultrasonography and pelvic CT showed a uterine mass that was not investigated further because of the presence of vaginal adhesions. There was no enlargement of the pelvic lymph node.

The patient was put on chylothorax diet. Diuretic treatment was increased, yielding a negative balance of $17 \mathrm{~kg}$ over one month. The clinical symptoms improved markedly with complete resolution of the ascites. Only a little fluid remained in the Douglas' sac, as demonstrated by ultrasonography. The pleural effusion remained stable and the triglyceride level in pleural fluid was $47 \mathrm{mg} \cdot \mathrm{dL}^{-1}$. A therapeutic thoracocentesis was performed and a chest tube was inserted to treat iatrogenic pneumothorax. Seven days later, only a few millilitres of pleural fluid drained each day and the tube was removed. The patient was discharged with diuretic treatment and little pleural fluid.

One month later, the patient was readmitted for atrial fibrillation and heart failure. The chest radiograph showed left pleural effusion, and the abdominal ultrasonography

Table 1. - Biochemical characteristics of the pleural effusion and ascites fluids.

\begin{tabular}{lcc}
\hline & Pleural fluid & Ascitic fluid \\
\hline $\mathrm{pH}$ & 7.34 & \\
Leucocytes cells $\cdot \mathrm{mm}^{-3}$ & 570 & 730 \\
Lymphocytes \% & 45 & 70 \\
Glucose $\mathrm{mg} \cdot \mathrm{dL}^{-1}$ & 108 & 117 \\
Total protein $\mathrm{g} \cdot \mathrm{dL}^{-1}$ & 2.54 & 3.94 \\
$\mathrm{LDH} \mathrm{U} \cdot \mathrm{L}^{-1}$ & 89 & 78 \\
Amylase U$\cdot \mathrm{L}^{-1}$ & 48 & 42 \\
Triglyceride $\mathrm{mg} \cdot \mathrm{dL}^{-1}$ & 262 & 504 \\
Cholesterol $\mathrm{mg} \cdot \mathrm{dL}-1$ & 52 & \\
\hline
\end{tabular}

LDH: lactate dehydrogenase. 
found mild ascites. In the next few days, her state deteriorated and she died.

The autopsy revealed severe diffuse arteriosclerosis, with arteriosclerotic coronary artery disease, biventricular hypertrophy, aneurysmatic dilatation of the left ventricle, and nephrosclerosis. The liver was nodular, and the histological findings were compatible with venous stasis. A serous pleural effusion of $750 \mathrm{~mL}$ was present, and a uterine leiomyoma was found. There were no enlarged lymph nodes in the mediastinum or retroperitoneum.

\section{Discussion}

The diagnosis of chylothorax is made when the pleural fluid triglyceride level is above $110 \mathrm{mg} \cdot \mathrm{dL}^{-1}$ [7]. Chylothorax and chylous ascites are usually produced by obstruction and disruption of thoracic duct, most frequently as a result of trauma, neoplasm or tuberculosis. Occasionally, other diseases have been reported as being the cause of chylothorax or chyloperitoneum, such as liver cirrhosis, superior vena cava thrombosis or nephrotic syndrome. On rare occasions, heart failure secondary to various causes produces chylothorax or chylous ascites [3-6].

Chylous ascites may be produced in heart failure by two mechanisms:

1. High venous pressure increases the abdominal lymph production secondary to an augmented capillary filtration. The lymph flow of the thoracic duct can increase by up to 12 fold the normal rate, but the stiffness of the venolymphatic junction in the neck limits lymphatic flow [8].

2 . High pressure in the left subclavian vein reduces lymphatic drainage.

As a result of the restricted lymphatic drainage, lymphatic venous collaterals form but cannot handle the normal lymph flow. The chylous fluid leaks into the peritoneal cavity or produces protein-losing enteropathy as a result of the rupture of dilated intestinal lacteals [9]. Moreover, chylothorax has been described as a result of mitral stenosis with pulmonary hypertension and right heart failure $[5,6]$. The mechanisms have not been completely explained; but high venous pressure in the left subclavian vein may contribute.
In our case, both cavities contained chylous fluid. Pathogenetically, both mechanisms described may have been involved. In addition, chylous ascites could have moved from the peritoneum into the thorax across a diaphragmatic defect, such as in cirrhotic pleural effusion [10].

Whatever the mechanisms responsible, the high prevalence of severe right heart failure and the rare presentation of chylous ascites and chylothorax, suggest that other unknown factors, such as lymphatic abnormalities, may play a role in the pathogenesis.

\section{References}

1. Marshall JB, Pola L. Chylous ascites secondary to constrictive pericarditis: a discussion of pathophysiologic mechanisms. Dig Dis Sci 1982; 27: 84-86.

2. Savage MP, Munoz SJ, Herman WM, Kusiak VM. Chylous ascites caused by constrictive pericarditis. Am J Gastroenterol 1987; 82: 1088-1090.

3. Hurley MK, Emiliani VJ, Comer GM, Patel A, Navarro C, Maiki CO. Dilated cardiomyopathy associated with chylous ascites. Am J Gastroenterol 1989; 84: 1567-1569.

4. Levy P, Abadia R, Christoforov B, Cremer GA. Ascite chyleuse compliquant une cardiopathie ischémique. Presse Méd 1985; 14: 1291.

5. Brenner WI, Boal BH, Reed GE. Chylothorax as a manifestation of rheumatic mitral stenosis. Chest 1978; 73: 672-673.

6. Molina Boix M, Ortega González G, Montoya Martinez JJ, Campos Peris V, García García J, Ruiz Ros JA. Quilotórax secundario a insuficiencia cardiaca. Rev Clin Esp 1987; 181: 507-509.

7. Staats BA, Ellefson RD, Budahn LL, Dines DE, Prakash UB, Offord K. The lipoprotein profile of chylous and nonchylous pleural effusions. Mayo Clin Proc 1980; 55: 700-704.

8. Dumont AE, Clauss RH, Reed GA, Tige DA. Lymph drainage in patients with congestive heart failure: comparison with findings in hepatic cirrhosis. $N$ Engl J Med 1963; 269: 949-952.

9. Wilkinson P, Pinto B, Senior JR. Reversible proteinlosing enteropathy with intestinal lymphangiectasia secondary to chronic constrictive pericarditis. $N$ Engl J Med 1965; 173: 1178-1181.

10. Light RW. Transudative pleural effusions. In: Light RW, ed. Pleural Diseases. Philadelphia, Lea \& Febiger, 1990; pp. 85-95. 